\title{
PROJEKAT ENTERIJERA PRODAVNICE MLEKA I MLEČNIH PROIZVODA SA RESTORANOM
}

\section{INTERIOR DESIGN OF DAIRY STORE WITH A RESTAURANT}

\author{
Tamara Lazić, Fakultet tehničkih nauka, Novi Sad
}

\section{Oblast - ARHITEKTURA}

Kratak sadržaj -Ovaj rad bavi se analizom i definisanjem programa prodavnice mleka $i$ mlečnih proizvoda, gde se pored komercijalne, istražuje i potencijal drugih namena, kako bi se zadovoljile savremene potrebe društva i obezbedila ekonomska i društvena održivost programa. Kroz revitalizaciju odabrane lokacije formira se multifunkcioni prostor sa komercijalnom, uslužnom i edukativnom namenom, čime se stvara platforma za uspešno plasiranje i promociju proizvoda.

Ključne reči: Enterijer, Mlekara, Prodavnica, Restoran

Abstract - This thesis analizes and defines the typology and program of dairy store, and explores the potential of other purposes besides it's commercial purpose, all in favor of accomodating the needs of modern society and providing economical and social sustainability. Through the revitalization of the chosen location, the project forms a multifunctional space, with commercial, hospitality and educational services, and therefor creates a platform for successful placing and promotion for the product.

Keywords: Interior, Dairy, Store, Restaurant

\section{UVOD}

Tema i zadatak ovog rada svodi se na redefinisanje programa i funkcije savremene tipologije mlekare, kroz analizu, dizajn i revitalizaciju odabranog prostora. Savremeni trendovi unutar prehrambene industrije mlečnih produkata iziskuju adaptaciju i stvaranje novih pristupa plasiranju, promociji i brendiranju proizvoda. Proširivanjem funkcije mlekare na način na koji ona postaje centar komunikacije, edukacije i promocije svih mlečnih proizvoda, utičemo na samu mikrosredinu u kojoj se mlekara nalazi, povezujući je sa uspešnim primerima revitalizacije prostora iz nepostredne okoline, koristeći kontekst u službni kako objekta tako i programa. Dizajn postaje metod naglašavanja i korišćenja najupečatljivijeg aspekta lokacije, to je njeno industrijsko nasleđe.

\section{ANALIZA PROGRAMA}

\subsection{Uvodno razmatranje}

Proizvonja mleka i mlečnih proizvoda duboko je utkana u istoriju ovih prostora. Jedan od glavnih obeležja nacionalne kuhinje jeste upravo ovaj bogat asortiman različitih mlečnih proizvoda poput kajmaka, milerama, kisele pavlake, raznih vrsta sireva, kiselog mleka i ostalih specijaliteta.

\section{NAPOMENA:}

Ovaj rad proistekao je iz master rada čiji mentor je bila dr Ivana Miškeljin, docent.
Osim industrijske proizvodnje mleka i mlečnih proizvoda značajan je i uticaj male, lokalne i domaćinske proizvodnje, koja je veoma zastupljena u Srbiji. Sve to ukazuje da se tradicija ne samo održava, već doživljava ekspanziju, time je potreba za prostorom koji će obuhvatiti sve male, lokalne proizvođače mleka i mlečnih proizvoda pod jedan krov, gde mogu da plasiraju sve svoje proizvode, obrazložena i očigledna [1].

\subsection{Definisanje programa}

Da bi se adekvatno promovisala mlekarska industrija, na lokalnom nivou, potrebno je obuhvatiti što veći asortiman proizvoda na jednom mestu. Kao jedan od glavnih aspekata promocije lokalnih proizvoda je edukacija, izlaganje i degustacija izloženih artikala, sve sa krajnjim ciljem njihovog plasiranja na lokalno tržište i promocijom $u$ komercijalne svrhe. Sagledavanjem svih navedenih kriterijuma i aspekata uticaja mleka na prehrambenu industriju, dolazi se do potrebe da se materijalizuje prostor koji će zadovoljiti sve potrebe i vidove konzumacije mleka kroz oblik uslužne delatnosti. Formiranjem prostora za degustaciju, gde se novi proizvodi i proizvođači mogu reklamirati daje dodatnu vrednost prodavnici. Isti taj prostor može biti pogodan za održavanje radionica. Dodavanjem restorana, $\mathrm{u}$ kojem se poslužuju jela bazirana na mlečnim proizvodima koja se izlažu u objektu, program se uzdiže na novi, viši nivo. Stvaranjem prostora mešovite funkcije, komercijalne, edukativne i uslužne, stvara se zanimljiv i održiv sadržaj.

\subsection{Uticaj programa na odabir lokacije}

Ideja da se mlekara izvuče iz konteksta industrijske delatnosti prebaci u uslužni kontekst iziskuje lokaciju koja je prijemčiva sličnim intervencijama. Jedno od takvih područja, koje je svojim industrijskim začecima predstavljalo grupni napredak i razvitak industrije na lokalnom nivou, a u današnje vreme postaje simbol revitalizacije napuštenih i zastarelih tehnologija i zanata, kao i novo žarište savremenih modela komercijalnih i uslužnih sadržaja, jeste Kineska četvrt u Novom Sadu.

\section{PROJEKAT ENTERIJERA}

\subsection{Analiza lokacije}

\subsection{1 Šira situacija}

Kineska četvrt u Novom Sadu nalazi se unutar stambene zone, Limana 3, u neposrednoj blizini Dunava, mosta Slobode, i značajnih gradskih saobraćajnica poput bulevara Oslobođenja, bulevara Cara Lazara i ulice Narodnog fronta, sa kojima je dobro povezana sa ostatkom grada kako kolskim tako i biciklističkim saobraćajem. Još jedan bitan faktor lokacije jeste neposredna blizina gradskog kupališta Štrand, i šetališta Sunčani kej. 


\subsubsection{Uža situacija}

Unutar same Kineske četvrti, koja je i dalje u fazi razvoja i revitalizacije, nalaze se razne zanatske radionice, kulturni centar Fabrika i klubovi Qaurter i Firchie Think Tank Studio, kao i restorani brze hrane. Program ovog projekta predstavlja upravo kombinaciju ovih sadržaja i time se savršeno uklapa u ovaj prostor.

\subsubsection{Istorijat}

Početkom dvadesetih godina 19. veka po dogovoru Grada i vojske, razrušeno je staro utvrđenje Mostobran i time konačno omogućena izgradnja na obali Dunava.

Godine 1921. Savet grada Novog Sada doneo je više odluka o prodaji gradskog zemljišta, među kojima je i zamljište na Limanu, koje je pripalo braći Kramer, koji podižu fabriku žice sa stanovima za radnike, a Uredu za graničnu trgovinu Republike Čehoslovačke za podizanje stovarišta, danas poznatog kao Češki magacin.

Tokom 1947. godine ovaj prostor zauzima fabrika Petar Drapšin, koja proizvodi zavrtnje, kao i žičanu i gvozdenu robu. U periodu između 1956. i 1974. godine dolazi do postepenog preseljenja fabrike na nove lokacije.

Nakon 1974. godine pa do kraja osamdesetih godina objekti na području Kineske četvrti stoje prazni. U ove oronule i zapuštene objekte tada se useljavaju zanatlije, automehaničari, stolari, kao i mnogi drugi.

Danas ovo područje poprima obrise novog alternativnog kulturno-umetničkog centra, gde se pored zanatskih radionica useljavaju umetnici, otvaraju ateljei, klubovi i kulturni centri [2].

\subsection{Koncept}

Glavni zadatak ovog projekta jeste povezivanje svh zadatih funkcija unutar odabranog prostora na adekvatan i funkcionalan način, a da se prilikom intervencija ispoštuje istorija lokacije. Tri glavne namene su uslužna, komercijalna i edukativna.

Cilj je formiranje kvalitetnog, slobodnog i prijatnog prostora koji će privući i zadržati ljude, i zainteresovati ih za proizvode koji se ovde izlažu i nude. Upotrebom istih materijala, inspirisanih istorijom lokacije, dobijamo kontinuitet unutar prostora i povezanost delova u celinu. Koristeći iste elemente enterijera u svim delovima prostora formiramo jedinstvenu celinu i povezujemo sve namene $u$ njemu.

\subsection{Funkcionalna podela}

Funkcionalna podela prostora jasno je uočljiva na osnovi, gde se mogu razaznati odvojene zone na osnovu funkcije i namene. Budući da je prostor formiran spajanjem 3 zasebne celine unutar objekta, one su ujedno bile i početna tačka pri podeli prostora. Zasebne celine unutar dva identična bloka, koja su medjusobno spojena novim, probijenim prolazom su podeljena i po funkciji, gde se u jednom nalazi prostor za izlaganje namirnica, a drugi blok dobio je funkciju kafića i restorana, oba otvorenog i javnog karaktera. Treći, manji blok ustupljen je za potrebe magacina, kuhinje restorana i prostorijama za osoblje, sa restriktivnim pristupom samo za zaposlene. Unutar javnih celina formirane su prostorije toaleta, zatim pomoćnih prostorija i pristupa magacinu. Nadomak manjeg bloka deo prostora pripao je svlačionicama za zaposlene. Iznad novih, implementiranih prostorija unutar otvorenog prostora dva bloka formirana je galerija.

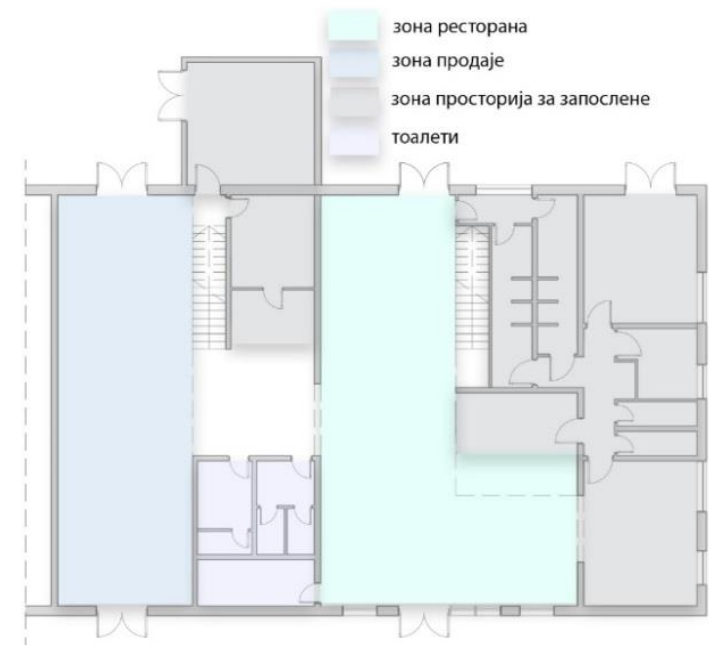

Slika 1. Funkcionalna podela prostora prizemlja.

зона ресторана

зона радионице/дегустације

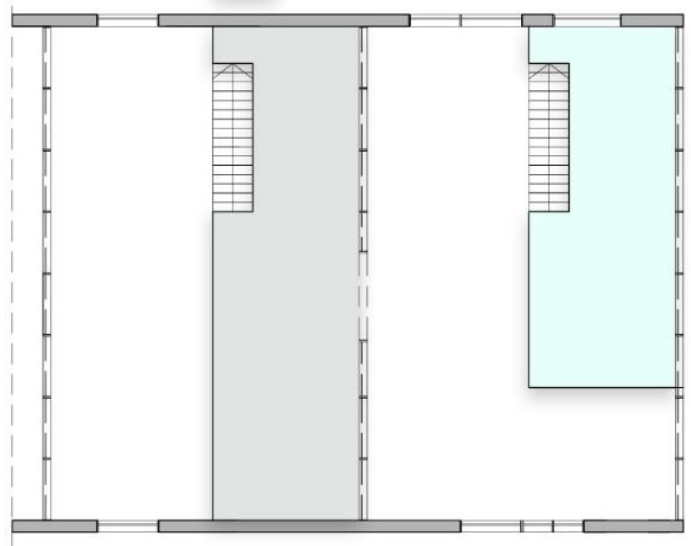

Slika 2. Funkcionalna podela prostora galerije.

\subsection{Konstrukcija}

Glavni konstruktivni elementi su betonski stubovi i grede, u kombinaciji sa nosećim zidovima od opeke i metalnom krovnom konstrukcijom.

Što se novih intervencija tiče, dodati zidovi su pregradni, osim zidova koji nose stepenice u oba dela prostora, a ujedno nosi i deo konstrukcije galerije. Noseći zid između dva bloka koji je probijen na mestu prolaza, adekvatno je rešen po pitanju nosivosti implementiranjem čeličnog rama, koja se uklapa u enterijer i njegovu materijalizaciju Stepenice su metalne, sa punim ramom i perforiranom gazištem, a u prostoru deluju lagano, kao da lebde.

Nova galerija se na dve strane oslanja na spoljašnje zidove debljine $38 \mathrm{~cm}$ i noseći zid stepenica, čime je postignuta potrebna stabilnost.

\subsection{Fasada}

Fasada je sačuvana u svom originalnom stanju u pogledu materijala, a to je fasadna opeka. Inervencije unutar prostora su zahtevale pomeranje i uklanjanje otvora, kako vrata tako i prozora, što je uticalo i na sam izgled fasade. Međutim, bitno je naglasiti da inako ne na svom originalnom mestu, otvori su od istog materijala, metalni ramovi sa podelama crne boje, čime se vidljivost intervencija svodi na minimum. 


\subsection{Materijalizacija}

Glavni uticaj na izbor materijala svakako je imala istorija objekta i samog lokaliteta. Budući da novoprojektovani enterijer zauzima prostor nekadašnje fabrike proizvoda od metala upravno taj materijal postaje dominantan $u$ prostoru. Osim što je deo istorije, deo je i već postojećih elemenata kao što je krovna konstrukcija i prozori. Dominanti materijali su metal, beton, i sjajne bele pločice, a zastupljene boje su crna, bela i nijanse sive, sa akcentima zelene $u$ vidu vegetacije. Obrada poda je višestruka, a najzastupljeniji materijal ja liveni beton sa sjajnom završnom obradom, koji daje neutralnu podlogu enterijeru. U kombinaciji sa njim upotrebljen je liveni epoksidni pod bele boje sa sjajnom završnom obradom, koji asocira na razliveno mleko. Deo šanka i kase naznačen je upotrebom keramičkih pločica crno beleboje. Podne led trake služe da naglase linije kretanja i akcentuju određene delove enterijera.

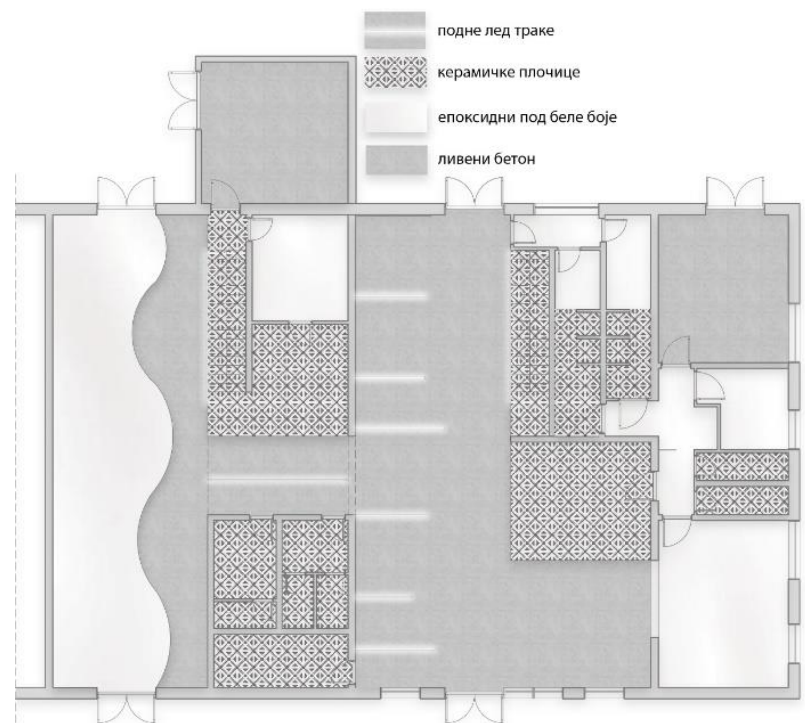

Slika 3. Prikaz obrade poda prizemlja.

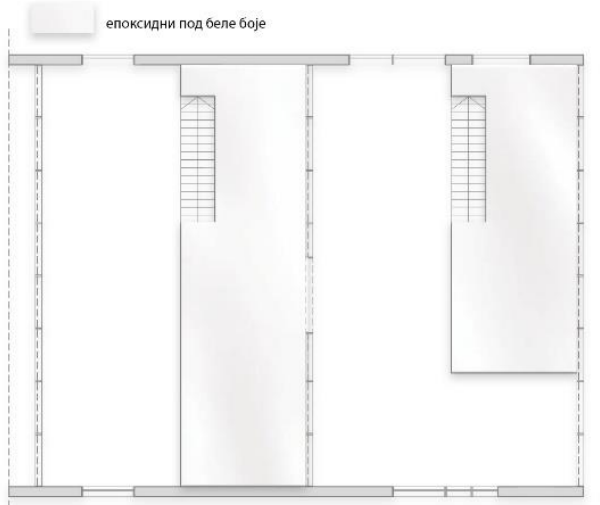

Slika 4. Prikaz obrade poda galerije.

Zidovi su ogoljeni i vraćeni u originalno stanje, gde se vidi konstruktivni materijal zidova, a to je opeka. Obrada zidova je mešovita, gde su na visini od $2 \mathrm{~m}$ obloženi sjajno belim pločicama a ostatak je ostavljen u opeci. Bele pločice imaju kako higijensku tako i estetsku funkciju. Veoma bitnu ulogu u enterijeru igraju pregrade, koje se sastoje od metalnih cevi dimenzija $50 \times 50 \mathrm{~mm}$, koje su raspoređene $\mathrm{u}$ određenim razmacima, $\mathrm{u}$ zavisnosti od potrebe, čime se reguliše transparentnost i naznačava razlika između slobodnih zona i zona sa određenom restrikcijom kretanja. Novoprojektovani kubusi unutar prostora obloženi su crnim cevima koje su gušće zbijene u delovima sa restriktivnim pristupom, a ređe ka slobodnim zonama. Bele cevi postavljene su na razmaku od $150 \mathrm{~mm}$ jedna od druge, i nalaze se u gornjim delovima enterijera, i naznačavaju poziciju galerije, a ujedno služe i kao element rasvete. [3]

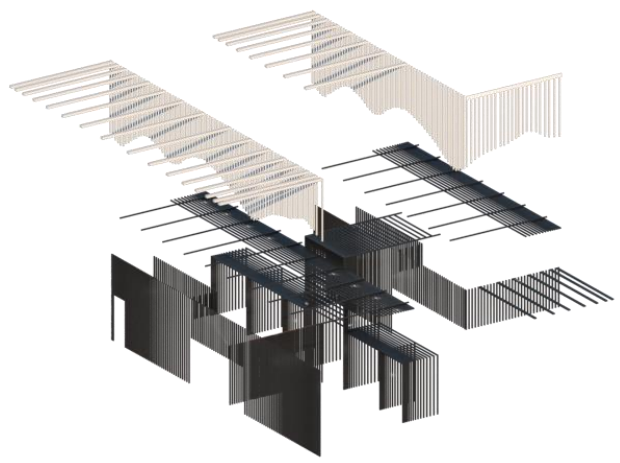

Slika 5. Prikaz grupa metalnih elemenata enterijera.

\subsection{Mobilijar}

Prilikom izbora mobilijara glavnu ulogu igrao je materijal. Stolice i stolovi produkti su dizajnerske firme Hay. Lagane, transparentne stolice crne boje se savršeno uklapaju u ovaj enterijer zahvaljujući tankim horizontalnim elementima ove serije stolica pod nazivom HayHee.

Stolove, takođe istog proizvođača, karakteriše minimalizam, jasne linije i sjajna obrada. Ukontrastu sa crnim stolicama izabrani su beli stolovi , koji ujedno asociraju na teksturu mleka. Mobilijar za separe dizajniran je posebno za potrebe prostora, i čini ga konstrukcija od crnih, metalnih šipki sa mekanim jastucima sive boje.

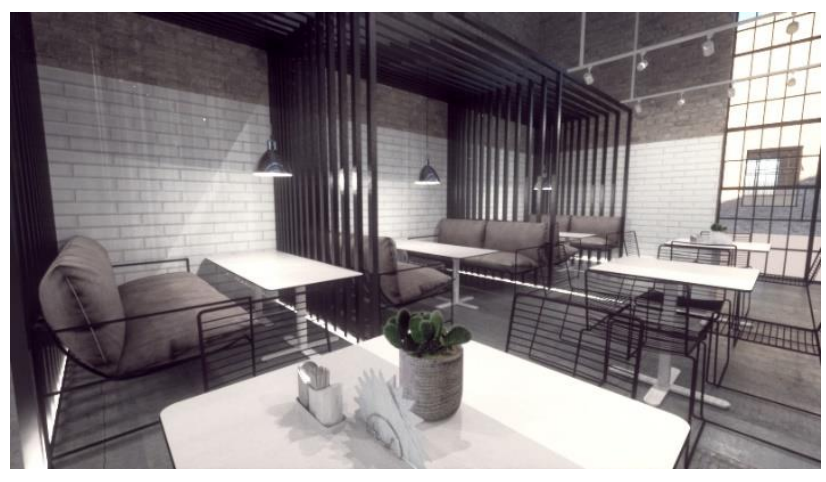

Slika 6. Prikaz nameštaja u enterijeru.

Još jedan bitan element mobilijara su police za izlaganje sastavljene od kutija metalne konstrukcije obojenih $\mathrm{u}$ belo, kose su naslagane jedna na drugu, u zavisnosti od potrebe. Ove kutije su transparentne, sa otvorenim frontovima, osim delova koji su zatvroeni metalnom mrežom. Ovaj element enterijera predstavlja omaž bivšem postrojenju fabrike koja se ovde nekada nalazila, koja se bavila između ostalog, proizvodnjom žičanih elemenata i mreža od metala. 


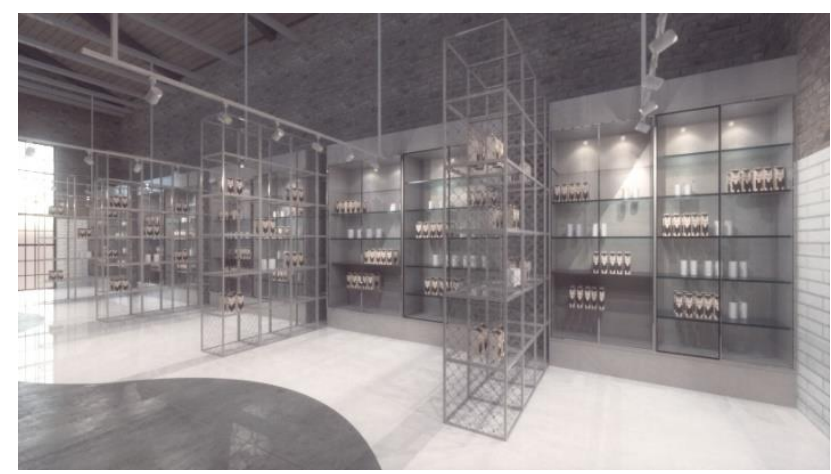

Slika 6. Prikaz polica i frižidera za izlaganje.

\subsection{Rasveta}

Rasveta unutar ovog enterijera je veoma raznolika. Kao jedan od glavnih kvaliteta prostora možemo navesti krovne prozore koji zaista daju poseban karakter prostoru, kao i veliku količinu pripodne svetlosti. Veliki stakleni otvori na fasadi takođe propuštaju dosta prirodne svetlosti što znatno poboljšava atmosferu prostora.

Pored dnevne svetlosti veoma je važno obezbediti i dobro veštačko osvetljenje koje će biti pravilno raspoređeno. Sistem osvetljenje sastoji se iz kombinacija direktnog i indirektnog svetla, i kombinacija ova dva tipa, zajedno sa prirodnim svetlom daje ovom prostoru određen šarm, kvalitet i doprinosi atmosferi.U skolpu ovog enterijera imamo šest različitih elemenata rasvete.

Prvi kojim ćemo se baviti jeste spot svelta na šinama dužine $3 \mathrm{~m}$, koja vise sa metalne konstrukcije, i osvetljavaju prostor prolaza i izložbenog dela enterijera. Spot svetla su pozicionirana taako da naglase određene delove prostora.

Viseći lusteri Laito L, marke SeedDesign, sa sjajnom, hormiranom završnom obradom služe da osvetle stolove šank, kao i pult za kasu. Sjajna obrada reflektuje okolinu i stvara zanimljiv efekat $u$ enterijeru, bez preveliko skretanja pažnje na sam element.

Led svetla na plafonu služe kao rasveta za prostorije za zaposlene, toalete, kao i prolaze i komunikaciju unutar prostora.

Trakasta led svetla primenjena su u prostorijama magacina, kao i unutar kuhinje restorana.

Akcentovana svetla u vidu led traka, koje se nalaze na podu unutar enterijera, služe da sugerišu i naglase linije kretanja unutar prostora.

Još jedan dominantan element prostora jeste metalna konstrukcija sačinjena od cevi bele boje, koje vise sa plafona, i koje na svojim krajevima imaju led svetla. Ovaj element daje specifičan karakter prostoru i naglašava poziciju galerija i prostornu kompoziciju enterijera [4].

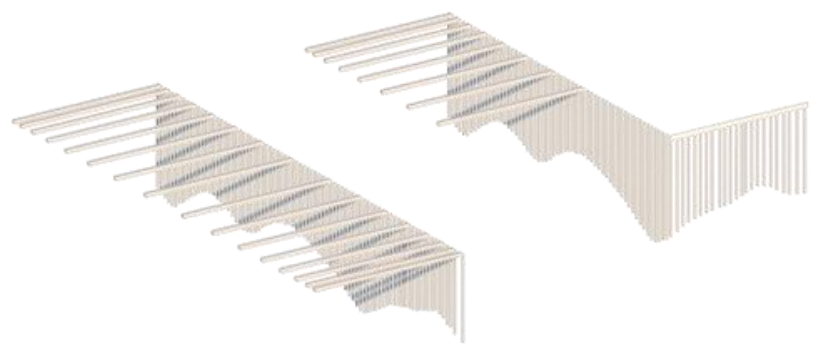

\section{ZAKLJUČAK}

Stvaranje Mlekare kao brenda prevazilazi čistu rekonstrukciju i revitalizaciju objekta unutar Kineske četvrti. Stvaranje nove fokalne tačke unutar šire sfere uticaja, koja je već sada dalekosežna, otvara nove mogućnosti, kako za samu Mlekaru tako i za njenu okolinu. Kontekst Kineske četvrti postaje još raznovrsniji, slojevitiji i aktivniji, a sve u službi očuvanja industrijskog i zanatskog duha koji dominira ovim prostorom.

Dizajn u službi ovakvih faktora postaje višeslojan, bez potrebe da bude dominantan i nametljiv, ali vrlo uticajan i neoboriv. Raznovrsnost ponude proizvoda koji se plasiraju, zadovoljavajući svačiji ukus i nutritivne zahteve, otvaraju novi prostor i daju mu mogućnost transformacije kroz korišćenje različitih funkcija ovog jedinstvenog prostora.

Revitalizacija nije samo metod promene zatečenog stanja odabranog objekta već i način posmatranja konteksta, funkcije i pristupa kako se doživljava prostor koji predstavlja savremena mlekara.

Predloženo rešenje doprinosi tome da ovaj prostor, unutar same Kineske četvrti, postane nova tačka, cilj kretanja kao i mesto zaustavljanja, ne samo uže okoline koja obuhvata Limane, Sunčani kej i plažu Štrand, već i celog Novog Sada, pa i šire.

Mogućnost edukacije o lokalnim kulturama i tradicijama konzumacije i proizvodnje plečnih proizvoda predstavlja jedan od glavnih doprinosa ovog projekta prostoru koji zauzima i redefiniše svoju korist.

\section{LITERATURA}

[1] https://agroekonomija.wordpress.com/2011/01/21/proizvodnja-mleka-i-mlecnih-proizvoda-u-republicisrbiji/ (septembar 2018)

[2] D. Stančić, "Umetnička topografija Novog Sada", Matica Srpske, Novi Sad, 2014.

[3] E. Neufert, "Architect's data", Wiley-Blackwell, 2000.

[4] P. Zumthor, "Atmospheres", Birkhauser-Publishers for Archirecture, Basel, Boston, Berlin, 2006.

\section{Kratka biografija:}

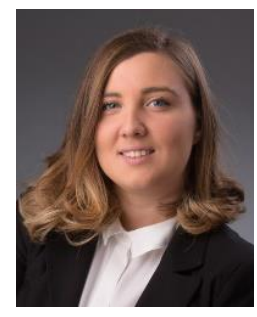

Tamara Lazić rođena je u Novom Sadu 1990. god. Diplomski-master rad na Fakultetu tehničkih nauka iz oblasti Projektovanje enterijera odbranila je 2018.god.

Ivana Miškeljin rođena je u Zrenjaninu, 1982. godine. Doktorirala je na Fakultetu tehničkih nauka u Novom Sadu 2014. godine. Oblasti interesovanja su arhitektonsko projektovanje i projektovanje enterijera. 